\title{
UPAYA MENINGKATKAN MOTIVASI BELAJAR SISWA KELAS VI MELALUI MODEL PEMBELAJARAN CONTEXTUAL TEACHING AND LEARNING DI SD NEGERI 164522 TEBING TINGGI
}

\author{
Cimalem \\ Guru SD Negeri 164522 \\ Email: cimalembangun@gmail.com
}

\begin{abstract}
Abstrak
Penelitian ini di latarbelakangi oleh rendahnya persentase ketercapaian atas Kriteria Ketuntasan Minimal (KKM) yang diperoleh siswa kelas VI SD Negeri 164522 Kota Tebing Tinggi dari jumlah siswa 34 orang yang mengikuti ulangan harian pada materi pelajaran permainan bola basket . Adapun hasil PTK ini adalah pembelajaran dengan metode Kooperatif model Teams Games Tournament. Hasil pelaksanaan penelitian tindakan kelas yang berlangsung menggunakan 2 siklus melalui metode pembelajaran contextual teaching and learning dalam pembelajaran pendidikan jasmani dan kesehatan pada permainan bola basket ternyata sudah cukup efektif terhadap peningkatan hasil belajar siswa. Siklus I ( $44 \%$ ), Siklus II ( 85,2 \%).
\end{abstract}

Kata Kunci : Pengertian Belajar, Model pembelajaran CTL

\section{PENDAHULUAN}

Sekolah SD Negeri 164522

Tebing Tinggi berada di Jalan KL.Yos Sudarso Komplek SMA Negeri 3 Kelurahan Tanjung Marulak Kecamatan Rambutan. Kondisi Orang Tua di SD Negeri164522 Tebing Tinggi sebagian besar berprofesi sebagai petani dan pedagang.. Sebagai seorang pendidik, peneliti menyadari Pendidikan Jasmani, Olahraga dan Kesehatan (Penjaskes) di sekolah merupakan jalur formal yang berperan mendidik siswa untuk peduli akan pentingnya kesehatan. Melalui serangkaian kegiatan olahraga siswa di perkenalkan berbagai permainan misal : bola basket, lari, lempar lembing, bola basket, dsb. Dengan diperkenalkannya berbagai kegiatan ini di harapkan dapat menggugah minat siswa untuk mencintai olahraga.

Sehubungan dengan hal ini peneliti sekaligus juga berperan sebagai guru olahraga di sekolah ini. Peneliti mencoba menerapkan metode pembelajaran contextual teaching and learning (CTL) . Bertitik tolak dari latar belakang permasalahan tersebut di atas maka dalam penelitian ini penulis mengambil judul "Upaya meningkatkan motivasi belajar siswa kelas VI melalui model pembelajaran pada pelajaran penjaskes di SD Negeri 164522 Tebing Tinggi tahun pelajaran 2011/2012".

Berdasarkan uraian pada latar belakang di atas, dapat diidentifikasikan beberapa permasalahan sebagai berikut :

a. Guru monoton sehingga kondisi dikelas membosankan 
b. Guru hanya menggunakan alat peraga yang sudah jadi

c. Guru kurang Kreatif

d. Siswa kurang memahami pelajaran yang diberikan

Berdasarkan batasan masalah yang dikemukakan dalam penelitian ini maka peneliti merumuskan masalah dalam penelitian ini adalah sebagai berikut : apakah dengan menggunakan metode pembelajaran contextual teaching and learning dapat meningkatkan motVIasi belajar siswa dalam mata pelajaran Penjaskes pada materi ajar tekhnik bermain bola basket di kelas VI SD Negeri 164522 Tebing Tinggi Tahun Pelajaran 2011/2012.

Penelitian ini diharapkan dapat memberi manfaat sebagai berikut :

\section{Bagi Siswa}

a. Penelitian ini bermanfaat bagi siswa karena dapat meningkatkan keterampilan mereka dalam mata pelajaran Penjaskes pada materi ajar tekhnik bermain bola basketdi kelas VI SD Negeri 164522 Tebing Tinggi Tahun Pelajaran 2011/2012.

b. Meningkatkan kedisiplinan siswa SD Negeri 164522 Tebing Tinggi terutama dalam berolahraga.

c. Membantu siswa memiliki kemampuan berolahraga yang baik dan berprestasi sehingga memiliki jiwa yang moderat, dapat bekerjasama dengan kelompok dan di tengah masyarakat.

d. Memberi peluang kepada siswa untuk lebih aktif mengembangkan potensi dirinya terutama dalam meraih prestasi olahraga baik di tingkat lokal maupun nasional.

\section{Bagi Guru}

a. Penelitian ini bermanfaat bagi guru karena memberikan informasi dan konstribusi untuk meningkatkan motivasi belajar siswa melalui penerapan metode gabungan antara metode ceramah dan demonstrasi.

b. Dapatmeningkatkanprofesionalis me dan kinerja guru khususnya guru Penjaskes serta menambah wawasannya tentang penerapan metode gabungan antara metode ceramah dan demonstrasi.

\section{Bagi Sekolah}

a. Penelitian ini bermanfaat bagi sekolah karena dapat menjadi bahan masukan dan pertimbangan dalam meningkatkan ketuntasan dan prestasi belajar siswa, di SD Negeri 164522 Tebing Tinggi.

b. Penelitian ini bermanfaat bagi sekolah karena dapat memberi masukan atau sumbangan penelitian bagi peneliti lain yang melakukan Penelitian Tindakan Kelas (PTK).

c. Penelitian ini juga dapat bermanfaaat bagi sekolah terutama dalam meningkatkan kualitas pembelajaran. 


\section{KAJIAN TEORI}

\section{Hakekat Pendidikan Jasmani, Olahraga dan Kesehatan}

Pendidikan Jasmani pada dasarnya merupakan pendidikan melalui aktivitas jasmani untuk mencapai perkembangan individu secara menyeluruh. Namun demikian, perolehan keterampilan dan perkembangan lain yang bersifat jasmaniah itu juga sekaligus sebagai tujuan.

\section{Model Pembelajaran Contextual Teaching and Learning}

Pendekatan kontekstual

(Contextual Teaching and Learning/CTL) merupakan konsep belajar yang membantu guru mengkaitkan antara materi yang diajarkannya dengan situasi dunia nyata siswa dan mendorong siswa membuat hubungan antara pengetahuan yang dimilikinya dengan penerapannya dalam kehidupan mereka sebagai anggota keluarga dan masyarakat serta sebuah keterampilan.

Menurut Cord yang dikuti Nur ( 2001 ) menyatakan bahwa pendekatan kontekstual terjadi apabila siswa memproses informasi dan pengetahuan baru sedemikian rupa sehingga informasi tersebut bermakna bagi mereka dalam kerangka acuan mereka sendiri. Pola pendekatan kontekstual berbeda dengan pendekatan konvensional yang kita kenal selama ini

Model Pembelajaran CTL berdasarkan pemikiran Konstruktivis

$\begin{array}{cc}\text { Pembelajaran } & \text { konstuktivis } \\ \text { dalam pengajaran menerapkan }\end{array}$ pembelajaran kooperatif secara luas, berdasarkan teori bahwa siswa lebih mudah menemukan dan memahami konsep-konsep yang sulit jika mereka saling mendiskusikan masalah tersebut dengan temanya. ( Nur, 1999 )

\section{Kerangka Berfikir}

Dalam konsep paradigma pengajaran yang konservatif umumnya guru lebih sering menggunakan metode ceramah dan tanya jawab, serta tidak menggunakan media pembelajaran yang tepat, akibatnya siswa kurang aktif dalam pembelajaran dan minat siswa terhadap mata pelajaran Penjaskes juga menjadi rendah.

Berdasarkan permasalahan diatas, peneliti termotivasi untuk mengatasi masalah yang dihadapi siswa dalam proses pembelajaran dikelas khususnya dalam memahami konsep Keterampilan tekhnik bermain bola basket pada mata pelajaran Penjaskes di kelas VI SD Negeri 164522 Tebing Tinggi. Oleh karena itu diharapkan melalui modelling Berbasis CTL dapat meningkatkan prestasi belajar dan pemahaman siswa pada 
Keterampilan Tekhnik bermain bola basket di kelas VI SD Negeri 164522 Tebing Tinggi.

\section{Hipotesis Tindakan}

Menurut Winarno Surachmad (1982) bahwa: "Hipotesa adalah sebagai sebuah kesimpulan, tetapi kesimpulan ini belum final masih harus dibuktikan kebenarannya. Hipotesa adalah jawaban dugaan yang dianggap besar kemungkinannya untuk menjadi jawaban yang benar".

Dari kutipan uraian diatas peneliti membuat dugaan atau hipotesis tindakan dalam penelitian yang dilaksanakan di kelas VI SD Negeri 164522 Tebing Tinggi, yaitu : Melalui penerapan modelling Berbasis CTL pada keterampilan Tekhnik bermain bola basket, maka prestasi belajar siswa dapat ditingkatkan.

\section{METODOLOGI PENELITIAN}

Tempat, Waktu dan Subyek

\section{Penelitian}

Penelitian ini bertempat di Jalan KL Yos Sudarso Komplek SMA Negeri 3 Kelurahan Tanjung Marulak Kecamatan Rambutan SD Negeri 164522 Tebing Tinggi Tahun Pelajaran 2011/2012. Penelitian ini dilaksanakan pada bulan Januari Maret 2012. Subyek penelitian adalah siswa-siswi Kelas VI SD Negeri 164522 Tebing Tinggi Tahun Pelajaran 2011/2012. Dengan jumlah siswa 39 orang. 21 orang Perempuan dan 18 orang Laki-laki.

\section{Rancangan Penelitian}

Rancangan penelitian ini menggunakan konsep aksi pada Action Research oleh Hopkin (1985), yang terdiri dari dua siklus dan masing-masing siklus menggunakan empat komponen tindakan yaitu, Perencanaan, Tindakan, Observasi dan Refleksi. Penelitian terdiri atas 2 siklus yang disebut dengan Siklus 1 dan Siklus 2.

\section{Siklus 1}

\section{Rencana tindakan}

Kegiatan yang dilakukan adalah sebagai berikut :

1. Mengumpulkan data-data, dari pertemuan Musyawarah Guru Mata Pelajaran (MGMP) yang dilaksanakan dalam satu kali sebulan di tingkat sekolah tentang persoalan yang terjadi pada siswa ketika mengikuti kegiatan pembelajaran Penjaskes khususnya cabang olahraga Atletik.

2. Mengidentifikasi persoalan yang perlu mendapatkan tindakan, bahwa cabang olahraga Atletik khususnya pada materi tekhnik bermain bola basketdalam mata pelajaran Penjaskes selama ini dianggap merupakan materi yang sulit dilakukan.

3. Mengupayakan bagaimana agar siswa dalam mengikuti kegiatan pembelajaran 
Penjaskeskhususnya pada materi tekhnik bermain bola basketmempunyai minat yang tinggi.

4. Rencana Tindakan adalah memberikan materi tekhnik bermain bola basketdengan menerapkan model pembelajaran Modelling Berbasis CTL.

\section{Pelaksanaan Tindakan.}

Pelaksanaan tindakan akan dilaksanakan pada minggu pertama bulan Maret 2009. Panduan perencanaan yang telah dibuat dengan kegiatan sebagai berikut :

1. Membagi siswa menjadi kelompok putra dan kelompok putri

2. Kelompok putra dan putri pun kembali dibagi menjadi dua kelompok sama banyak

3. Memberikan penjelasan tentang materi yang diberikan

4. Menugaskan kepada masingmasing kelompok untuk mencontoh gerakan-gerakan yang dilakukan Guru sesuai dengan materi ajar tekhnik bermain bola basket

\section{Observasi}

Guru/Peneliti sekaligus sebagai observator dibantu oleh dua orang Guru lainnya melakukan observasi / pengamatan terhadap semua kejadian pada PBM untuk dijadikan acuan dalam membuat catatan (Vignette) dan pengisian lembar observasi yang telah dibuat selama proses pembelajaran tekhnik bermain bola basketdi lapangan sekolah .

\section{Refleksi}

Data yang diperoleh pada lembar observasi, dianalisis. Kemudian dilakukan refleksi. Pelaksanaan refleksi merupakan hasil observasi/ pengamatan peneliti pada saat melakukan observasi di lapangan sekolah. Tahap ini merupakan tahap akhir setiap siklus, peneliti menyimpulkan dan mengevaluasi jalannya kegiatan yang telah dilaksanakan

\section{Siklus ke 2}

\section{Rencana Tindakan}

Pada tahap ini peneliti membuat alternatif pemecahan masalah untuk mengatasi rendahnya keterampilan siswa dalam melakukan tekhnik bermain bola basketdengan langkahlangkah sebagai berikut :

a. Mengidentifikasi kelemahankelemahan yang terdapat pada siswa di siklus 1

b. Membuat RPP ke 2 tentang materi tekhnik bermain bola basket

c. Menganalisis materi RPP 2 tersebut diatas.

d. Menyiapkan objek lingkungan sebagai arena siswa untuk melakukan kegiatan tekhnik bermain bola basket

e. Menyiapkan lembar pengamatan atau observasi. 
f. Menyusun lembar observasi mengenai keterampilan siswa dalam PBM

\section{Pelaksanaan Tindakan}

Penerapan model Modelling Berbasis CTL dilakukan dengan menugaskan kepada masing-masing kelompok untuk mencontoh gerakangerakan yang dilakukan Guru sesuai dengan materi ajar tekhnik bermain bola basket . Pada Siklus ke dua ini juga, suasana pembelajaran masingmasing kelompok dilapangan dikondisikan agar tidak terlalu formal, maksudnya siswa bebas mengemukakan pendapatnya tentang materi ajar serta gerakan-gerakan yang dilakukan sesuai dengan kompetensi dasar yang ingin dicapai.

\section{Observasi}

Guru/Peneliti sekaligus sebagai observator dibantu oleh dua orang

\section{HASIL PENELITIAN DAN PEMBAHASAN}

Proses pengamatan dilakukan dengan menggunakan daftar chek dan catatan lapangan. Pada pelaksanaannya jumlah siswa seharusnya 39 anak. Namun pada waktu pelaksanaan, siswa yang hadir
Guru lainnya melakukan observasi / pengamatan terhadap semua kejadian pada PBM untuk dijadikan acuan dalam membuat catatan (Vignette) dan pengisian lembar observasi yang telah dibuat selama proses pembelajaran tekhnik bermain bola basket di lapangan sekolah. Data yang bersifat deskriptif kualitatif pada siklus ke dua ini lebih terperinci diperhatikan dan dianalisis agar hasil penelitian ini dapat lebih dipertanggungjawabkan hasilnya dan dapat diaplikasikan hasil temuannya kepada siswa di SD Negeri 164522 Tebing Tinggi khususnya kepada siswa di kelas VI pada mata pelajaran Penjaskes .

\section{Refleksi}

Tahap ini merupakan tahap akhir setiap siklus, peneliti menyimpulkan dan mengevaluasi jalannya kegiatan yang telah dilaksanakan Siklus II.

hanya berjumlah 34 siswa sedangkan 5 siswa lainnya berhalangan hadir. Dalam penelitian ini pembelajaran dilakukan yang dimulai dengan menganalisis situasi Kondisi Awal, Siklus Pertama dan Siklus Kedua yang hasilnya seperti terlihat berikut ini: 


\section{Hasil Kondisi Awal}

A. Minat Belajar Siswa terhadap tekhnik permainan bola basket

\begin{tabular}{|c|c|c|c|c|c|c|c|c|c|}
\hline \multirow[t]{2}{*}{ No } & \multirow[t]{2}{*}{ Aspek yang dinilai } & \multicolumn{2}{|c|}{$\begin{array}{l}\text { Sangat } \\
\text { tidak } \\
\text { Setuju }\end{array}$} & \multicolumn{2}{|c|}{$\begin{array}{l}\text { Tidak } \\
\text { Setuju }\end{array}$} & \multicolumn{2}{|c|}{ Setuju } & \multicolumn{2}{|c|}{$\begin{array}{l}\text { Sangat } \\
\text { setuju }\end{array}$} \\
\hline & & $\mathbf{F}$ & $\%$ & $\mathbf{F}$ & $\%$ & $\mathbf{F}$ & $\%$ & $\mathbf{F}$ & $\%$ \\
\hline 1 & $\begin{array}{l}\text { Saya senang belajar dengan } \\
\text { menggunakan model ceramah pada } \\
\text { materi Tekhnik bermain bola basket }\end{array}$ & 14 & $\begin{array}{c}41, \\
2\end{array}$ & $\begin{array}{l}1 \\
2\end{array}$ & 35,3 & 3 & 8,8 & 5 & 14,7 \\
\hline 2 & $\begin{array}{l}\text { Materi Tekhnik bermain bola } \\
\text { basket mudah dipahami dengan } \\
\text { menggunakan model ceramah }\end{array}$ & 16 & $\begin{array}{c}47, \\
1\end{array}$ & $\begin{array}{l}1 \\
3\end{array}$ & 38,2 & 3 & 8,8 & 1 & 2,9 \\
\hline 3 & $\begin{array}{l}\text { Saya banyak berinteraksi dengan } \\
\text { teman selama kegiatan belajar } \\
\text { mengajar dengan menggunakan } \\
\text { model ceramah }\end{array}$ & 15 & $\begin{array}{c}44, \\
1\end{array}$ & $\begin{array}{l}1 \\
2\end{array}$ & 35,3 & 5 & 14,7 & 2 & 5,9 \\
\hline 4 & $\begin{array}{l}\text { Dengan model ceramah saya dapat } \\
\text { memahami Tekhnik bermain bola } \\
\text { basket dengan baik }\end{array}$ & 16 & $\begin{array}{c}47, \\
1\end{array}$ & $\begin{array}{l}1 \\
4\end{array}$ & 41,2 & 1 & 2,9 & 3 & 8,8 \\
\hline 5 & $\begin{array}{lll}\text { Saya memperoleh } & \text { tambahan } \\
\text { pengetahuan setelah } & \text { mengikuti } \\
\text { kegiatan pembelajaran } & \end{array}$ & 13 & $\begin{array}{c}38, \\
2\end{array}$ & $\begin{array}{l}1 \\
5\end{array}$ & 44,1 & 4 & 11,8 & 2 & 5,9 \\
\hline 6 & 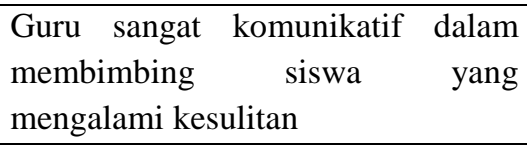 & 11 & $\begin{array}{c}32, \\
3\end{array}$ & $\begin{array}{l}1 \\
6\end{array}$ & 47,1 & 6 & 17,6 & 1 & 2,9 \\
\hline 7 & $\begin{array}{l}\text { Materi Tekhnik bermain bola basket } \\
\text { gampang dipelajari }\end{array}$ & 16 & $\begin{array}{c}47, \\
1\end{array}$ & $\begin{array}{l}1 \\
4\end{array}$ & 41,2 & 2 & 5,9 & 2 & 5,9 \\
\hline 8 & $\begin{array}{l}\text { Materi Tekhnik bermain bola basket } \\
\text { bermanfaat untuk dipelajari }\end{array}$ & 11 & $\begin{array}{c}32, \\
3\end{array}$ & $\begin{array}{l}1 \\
2\end{array}$ & 35,3 & 7 & 20,6 & 4 & 11,8 \\
\hline 9 & $\begin{array}{l}\text { Saya bosan belajar dengan model } \\
\text { ceramah }\end{array}$ & 3 & 8,8 & 5 & 14,7 & $\begin{array}{l}1 \\
5\end{array}$ & 44,1 & 11 & 32,3 \\
\hline 10 & $\begin{array}{c}\text { Saya berharap sekiranya } \\
\text { pembelajaran Penjaskes } \\
\text { menggunakan model /model } \\
\text { pembelajaran lain yang lebih } \\
\text { menarik. }\end{array}$ & 4 & $\begin{array}{c}11, \\
8\end{array}$ & 4 & 11,8 & $\begin{array}{l}1 \\
2\end{array}$ & 35,3 & 14 & 41,2 \\
\hline
\end{tabular}


Data yang diperoleh melalui hasil observasi pada kondisi awal , dari tabel diatas No. 1 menunjukkan banyaknya jumlah siswa senang belajar dengan menggunakan model ceramah pada Tekhnik bermain bola basket sangat tidak setuju $41,2 \%$, tidak setuju $35,3 \%$ dan setuju 8,8\% lebih besar persentase tidak setuju dan sangat tidak setuju.berarti siswa lebih menyenangi belajar dengan Guru memakai model yang lain.

Kondisi ini sebenarnya sudah sangat mengkhawatirkan bagi

kemajuan dan kualitas hasil pembelajaran apabila tidak dilakukan tindakan nyata untuk suatu perubahan. Berdasarkan inilah peneliti melihat pentingnya untuk melakukan Penelitian Tindakan Kelas dengan menerapkan model pembelajaran Modelling Berbasis CTL sebagai upaya melakukan pembaharuan dalam proses pembelajaran. Dengan harapan melalui penerapan model pembelajaran Modelling Berbasis CTL, peneliti berharap motivasi dan prestasi siswa akan dapat lebih meningkat.

\section{Hasil Siklus Pertama}

Setelah diberi penerapan mengenai metode CTL, Dapat dilihat dari data berikut :

\begin{tabular}{|c|c|c|c|c|c|c|c|c|c|}
\hline \multirow{2}{*}{$\begin{array}{l}\text { No. } \\
\text { Urut }\end{array}$} & \multirow[t]{2}{*}{ Nama siswa } & \multirow[t]{2}{*}{ Nilai } & \multicolumn{2}{|c|}{ Keterangan } & \multirow{2}{*}{$\begin{array}{l}\text { No. } \\
\text { Urut }\end{array}$} & \multirow[t]{2}{*}{ Nama siswa } & \multirow{2}{*}{$\begin{array}{c}\text { Nila } \\
\text { i }\end{array}$} & \multicolumn{2}{|c|}{$\begin{array}{c}\text { Keteran } \\
\text { gan }\end{array}$} \\
\hline & & & $\mathrm{T}$ & TT & & & & $\mathrm{T}$ & TT \\
\hline 1 & Andira sumanti & 80 & $\sqrt{ }$ & & 19 & Nabila lubis & 70 & $\sqrt{ }$ & \\
\hline 2 & Aris Mahendra & 70 & $\sqrt{ }$ & & 20 & $\begin{array}{l}\text { Novita Ade } \\
\text { Syafitri }\end{array}$ & 60 & & $\sqrt{ }$ \\
\hline 3 & Chyntia & 40 & & $\sqrt{ }$ & 21 & Nurhasanah & 70 & $\sqrt{ }$ & \\
\hline 4 & Christopel Gabriel & 80 & $\sqrt{ }$ & & 22 & Imam Hanapi & 80 & $\sqrt{ }$ & \\
\hline 5 & Deri agusman & 60 & & $\sqrt{ }$ & 23 & $\begin{array}{l}\text { Radhika } \\
\text { Ramadhani }\end{array}$ & 80 & $\sqrt{ }$ & \\
\hline 6 & Diah Agustina & 50 & & $\sqrt{ }$ & 24 & Rito pranata & 40 & & $\sqrt{ }$ \\
\hline 7 & Dony agustin & 80 & $\sqrt{ }$ & & 25 & Roni Rinaldi & 70 & $\sqrt{ }$ & \\
\hline 8 & Dwi suciadin & 60 & & $\sqrt{ }$ & 26 & Rovita Situkkir & 50 & & $\sqrt{ }$ \\
\hline 9 & Ega Erika & 80 & $\sqrt{ }$ & & 27 & Riki Irfandi & 80 & $\sqrt{ }$ & \\
\hline 10 & Fani veranza & 70 & $\sqrt{ }$ & & 28 & Rano Prayoga & 40 & & $\sqrt{ }$ \\
\hline 11 & Gabriel & 80 & $\sqrt{ }$ & & 29 & Ruben Saragih & 70 & $\sqrt{1}$ & \\
\hline 12 & $\begin{array}{l}\text { Hakiki Lestari } \\
\text { Nasution }\end{array}$ & 80 & $\sqrt{ }$ & & 30 & Sistra & 50 & $\sqrt{ }$ & \\
\hline 13 & Laila Hafni & 80 & $\sqrt{ }$ & & 31 & Sri Handayani & 70 & $\sqrt{ }$ & \\
\hline
\end{tabular}




\begin{tabular}{|l|l|l|l|l|l|l|l|l|l|}
\hline 14 & Lailan safira & 70 & $\sqrt{ }$ & & 32 & Ulfa & 60 & & $\sqrt{ }$ \\
\hline 15 & M. Riski Nasution & 40 & & $\sqrt{ }$ & 33 & Wika andriyani & 70 & $\sqrt{ }$ & \\
\hline 16 & M. Aznul Iqbal & 80 & $\sqrt{ }$ & & 34 & yose & 80 & $\sqrt{ }$ & \\
\hline 17 & Morlina Gultom & 80 & $\sqrt{ }$ & & & & & & \\
\hline 18 & $\begin{array}{l}\text { Melitri Roito } \\
\text { Sihombing }\end{array}$ & 60 & & $\sqrt{ }$ & & & & \\
\hline $\begin{array}{l}\text { Jumlah Skor 2280 } \\
\text { Jumlah Skor Maksimal Ideal 3500 } \\
\text { \% Skor Tercapai 66,85 }\end{array}$
\end{tabular}

Keterangan: $\mathrm{T}$ : Tuntas melakukan gerakan-gerakan sesuai

TT : Tidak Tuntas dengan ketentuan yang benar dalam

Jlh siswa yang tuntas : 23 tekhnik bermain bola basket . Guru

Jlh siswa yg blm tuntas: 11 memberikan bimbingan kepada

Klasikal : Belum tuntas siswa untuk meniru gerakan-gerakan

Siklus pertama terdiri dari 4 yang sudah dilakukannya.

tahap kegiatan, yakni kegiatan tentang tekhnik bermain bola basket

perencanaan, kegiatan pelaksanaan,

kegiatan observasi dan kegiatan

Pada Siklus 1, antusiasme refleksi. Pada tahap awal, kegiatan Guru maupun Siswa masih termasuk pembelajaran dengan model kategori Cukup Baik untuk pembelajaran Modelling Berbasis melaksanakan model pembelajaran CTL dilaksanakan sesuai dengan Modelling Berbasis CTL ini secara RPP siklus I yang telah optimal. Keadaan ini terjadi karena dipersiapkan. Selanjutnya kegiatan baik Guru maupun Siswa belum inti pembelajaran dimulai dengan pernah melakukannya sehingga menyampaikan tujuan pembelajaran masih menganggap model ini dan memberi informasi , Guru merupakan keadaan yang asing dan menerapkan model pembelajaran baru baginya.

Modelling Berbasis CTL dengan

\section{Hasil siklus kedua}

Dengan data yang dapat diamati adalah :

Tabel 4.8

\begin{tabular}{|c|c|c|c|c|c|c|c|c|c|}
\hline \multirow{2}{*}{$\begin{array}{l}\text { No. } \\
\text { Urut }\end{array}$} & \multirow[t]{2}{*}{ Nama siswa } & \multirow[t]{2}{*}{ Nilai } & \multicolumn{2}{|c|}{ Keterangan } & \multirow{2}{*}{$\begin{array}{l}\text { No. } \\
\text { Urut }\end{array}$} & \multirow[t]{2}{*}{ Nama siswa } & \multirow[t]{2}{*}{ Nilai } & \multicolumn{2}{|c|}{$\begin{array}{c}\text { Keterang } \\
\text { an }\end{array}$} \\
\hline & & & $\mathrm{T}$ & TT & & & & $\mathrm{T}$ & TT \\
\hline 1 & Andira sumanti & 80 & $\sqrt{ }$ & & 19 & Nabila lubis & 70 & $\sqrt{ }$ & \\
\hline 2 & Aris Mahendra & 70 & $\sqrt{ }$ & & 20 & $\begin{array}{l}\text { Novita Ade } \\
\text { Syafitri }\end{array}$ & 80 & $\sqrt{ }$ & \\
\hline 3 & Chyntia & 60 & & $\sqrt{ }$ & 21 & Nurhasanah & 70 & $\sqrt{ }$ & \\
\hline
\end{tabular}




\begin{tabular}{|c|c|c|c|c|c|c|c|c|c|}
\hline 4 & Christopel Gabriel & 70 & $\sqrt{ }$ & & 22 & Imam Hanapi & 50 & & $\sqrt{ }$ \\
\hline 5 & Deri agusman & 60 & & $\sqrt{ }$ & 23 & $\begin{array}{l}\text { Radhika } \\
\text { Ramadhani }\end{array}$ & 70 & $\sqrt{ }$ & \\
\hline 6 & Diah Agustina & 70 & $\sqrt{ }$ & & 24 & Rito pranata & 70 & $\sqrt{ }$ & \\
\hline 7 & Dony agustin & 70 & $\sqrt{ }$ & & 25 & Roni Rinaldi & 60 & $\sqrt{ }$ & \\
\hline 8 & Dwi suciadin & 80 & $\sqrt{ }$ & & 26 & Rovita Situkkir & 50 & & $\sqrt{ }$ \\
\hline 9 & Ega Erika & 70 & $\sqrt{ }$ & & 27 & Riki Irfandi & 70 & $\sqrt{ }$ & \\
\hline 10 & Fani veranza & 70 & $\sqrt{ }$ & & 28 & Rano Prayoga & 80 & $\sqrt{ }$ & \\
\hline 11 & Gabriel & 50 & & $\sqrt{ }$ & 29 & Ruben Saragih & 90 & $\sqrt{ }$ & \\
\hline 12 & $\begin{array}{l}\text { Hakiki Lestari } \\
\text { Nasution }\end{array}$ & 50 & & $\sqrt{ }$ & 30 & Sistra & 80 & $\sqrt{ }$ & \\
\hline 13 & Laila Hafni & 70 & $\sqrt{ }$ & & 31 & Sri Handayani & 70 & $\sqrt{ }$ & \\
\hline 14 & Lailan safira & 80 & $\sqrt{ }$ & & 32 & Ulfa & 80 & $\sqrt{ }$ & \\
\hline 15 & M. Riski Nasution & 70 & $\sqrt{ }$ & & 33 & Wika andriyani & 70 & $\sqrt{ }$ & \\
\hline 16 & M. Aznul Iqbal & 60 & & $\sqrt{ }$ & 34 & yose & 50 & & $\sqrt{ }$ \\
\hline 17 & Morlina Gultom & 70 & $\sqrt{ }$ & & & & & & \\
\hline 18 & $\begin{array}{l}\text { Melitri Roito } \\
\text { Sihombing }\end{array}$ & 70 & $\sqrt{ }$ & & & & & & \\
\hline \multicolumn{10}{|c|}{$\begin{array}{l}\text { Jumlah Skor } 2280 \\
\text { Jumlah Skor Maksimal Ideal } 3500 \\
\text { \% Skor Tercapai } 66,85\end{array}$} \\
\hline
\end{tabular}

Keterangan: $\mathrm{T}$ : Tuntas

TT : Tidak Tuntas

Jlh siswa yang tuntas : 27

Jlh siswa yg blm tuntas: 8

Klasikal

: Tuntas

Hasil tes siklus 2

menunjukkan peningkatan, dan sudah memenuhi indikator keberhasilan $(75 \%)$ yang telah ditetapkan, maka penelitian dihentikan pada siklus II.

\section{SIMPULAN DAN SARAN}

\section{Simpulan}

Dari hasil kegiatan pembelajaran yang telah dilakukan selama tiga siklus, dan berdasarkan seluruh pembahasan serta analisis yang telah dilakukan dapat disimpulkan sebagai berikut: a. Pembelajaran dengan modelling Berbasis CTL Pada Keterampilan Tekhnik bermain bola basketmemiliki dampak positif dalam meningkatkan prestasi belajar siswa yang ditandai dengan peningkatan ketuntasan belajar siswa dalam setiap siklus, yaitu siklus I $(44,1 \%)$, siklus II $(85,29 \%)$.

b. Penerapan modelling Berbasis CTL Pada Keterampilan Tekhnik bermain bola basketmeninjau kesulitan pada materi pelajaran mempunyai pengaruh positif, yaitu dapat meningkatkan motivasi belajar siswa yang ditunjukan dengan rata-rata jawaban siswa yang menyatakan 
bahwa siswa tertarik dan berminat dengan metode belajar aktif model meninjau kesulitan pada materi pelajaran sehingga mereka menjadi termotivasi untuk belajar.

c. Penerapan modelling Berbasis CTL Pada Keterampilan Tekhnik bermain bola basketmeninjau kesulitan pada materi pelajaran efektif untuk mengingatkan kembali materi ajar yang telah diterima siswa selama ini, sehingga mereka merasa siap untuk menghadapi ujian kenaikan kelas yang segera akan dilaksanakan.

\section{Saran}

Dari hasil penelitian yang diperoleh dari uraian sebelumnya agar proses belajar mengajar Penjaskes lebih efektif dan lebih memberikan hasil yang optimal bagi siswa, maka disampaikan saran sebagai berikut:

a. Untuk melaksanakan metode belajar aktif model meninjau kesulitan pada materi pelajaran memerlukan persiapan yang cukup matang, sehingga guru harus mampu menentukan atau memilih topik yang benar-benar bisa diterapkan dengan metode belajar aktif model meninjau kesulitan pada materi pelajaran proses belajar mengajar sehingga diperoleh hasil yang optimal.

b. Dalam rangka meningkatkan prestasi belajar siswa, guru hendaknya lebih sering melatih siswa dengan berbagai metode, walaupun dalam taraf yang sederhana, dimana siswa nantinya dapat menemukan pengetahuan baru, memperoleh konsep dan keterampilan, sehingga siswa berhasil atau mampu memecahkan masalahmasalah yang dihadapinya.

c. Perlu adanya penelitian yang lebih lanjut, karena hasil penelitian ini hanya dilakukan di Kelas VI SD Negeri 164522 Tebing Tinggi Tahun Pelajaran 2011/2012.

\section{DAFTAR RUJUKAN}

Ahmadi, Abu dan Supriyono W. 2004. Psikologi Belajar. Jakarta: Rineka Cipta

Ali, Muhammad. 1996. Guru Dalam Proses Belajar Mengajar. Bandung: Sinar Baru Algesindon.

Aqib, Zainal. 2009. Penelitian Tindakan Kelas untuk Guru. Bandung: CV. Yrama Widya.

Arikunto, Suharsimi. Dkk., 2006. Penelitian Tindakan Kelas. Jakarta: Bumi Aksara.

Arikunto, Suharsimi. 2002. Prosedur Penelitian Suatu Pendekatan Praktek. Jakarta: Rineksa Cipta

Arikunto, S. 2002. Dasar-dasar Evaluasi Pendidikan. Jakarta: Bumi Aksara. 
Departemen Pendidikan Nasional. 2003.

Departemen Pendidikan Nasional. 2005. Materi Pelatihan Terintegrasi

Matematika. Jakarta:

Depdiknas, Direktorat Jenderal. Pendidikan Dasar dan Menengah, dan Direktorat Pendidikan Lanjutan Pertama.

Dimyati dan Mudjiono. 2002. Belajar dan Pembelajaran. Jakarta: Rineka Cipta.Hadi, Sutrisno. 1982. Metodologi Research, Jilid 1. Yogyakarta: YP. Fak. Psikologi UGM.

Hadis, Abdul. 2006. Psikologi Dalam Pendidikan. Bandung: Alfabeta.

Hamalik, Oemar. 2003. Proses Belajar Mengajar. Jakarta: Bumi Aksara.

Hartutik. 2006. Efektivitas Pembelajaran Biologi SMA dengan Pendekatan Jelajah Alam Sekitar (JAS) berdasar Analisis SWOT dalam kemasan $C D$ Interaktif. Tesis: Program Pascasarjana Prodi Pend. IPA Unnes.

Hudojo, Herman. 1990. Strategi Mengajar Belajar Bahasa Indonesia , IKIP Malang: Malang.

Ibrahim, M. dkk., 2000. Pembelajaran Kooperatif.
Surabaya: UnVIersitas Negeri Surabaya.

Mariyana, Rita. 2005. Strategi Pengelolaan Lingkungan Belajar Di Taman KanakKanak. Departemen Pendidikan Nasional. Jakarta.

Ngalim, Purwanto, M. 1984. PrinsipPrinsip dan Teknik Evaluasi Pengajaran. Bandung: Remaja Rosdakarya.

Oemar, Hamalik. 2003. Proses Belajar Mengajar. Jakarta: PT. Bumi Aksara.

Pasaribu, I. L. Dkk，1982. Teori Kepribadian. Bandung: Tarsito.

Riduwan. 2004. Belajar Mudah Penelitian Untuk GuruKaryawan dan Peneliti Pemula. Bandung: Alfabeta.

Roestiyah, N.K. 1989. Masalahmasalah Ilmu Keguruan. Jakarta: Bina Aksara.

Rusyan, Tabrani. dkk, 1994. Pendekatan dalam Proses Belajar Mengajar. Bandung: Remaja Karya.

Sanjaya, Wina. 1991. Pembelajaran Dalam Implementasi Kurikulum Berbasis Kompetensi. Bandung: Kencana.

Simanjuntak, Lisnawaty. Dkk. 1992. Metode Mengajar 
Matematika 1. Bandung:

Rineka Cipta:

Sudjana, Nana. 1989. Penilaian

Hasil Proses Belajar

Mengajar. Remaja

Bandung: Rosdakarya.

Sukmadinata, Nana Syaodih. 2004.

Metode Penelitian

Pendidikan. Bandung:

PT. Remaja Rosdakarya.

1998. Dasar-dasar

Proses Belajar Mengajar.

Bandung : Sinar Baru

Algensindo.

Usman, Moh. Uzer. 1993. Upaya Optimalisasi Kegiatan Belajar Mengajar. :
Bandung: Remaja

Rosdakarya Offse,t

Wardhani. 2007. Pengertian Belajar. http://www.whandi.net/in dex.php?pilih=news\&

Mod=yes\&aksi=lihat\&id $=41$. (diakses 12 januari 2010).

Winkel. W.S. 1987. Psikologi Pengajaran. Jakarta Gramedia.

Yasa, Doantara. 2008. Metode Pembelajaran Kooperatif. http://ipotes.wordpress.co $\underline{\mathrm{m}}$

/2008/05/10metodepembelajaran-kooperatif. (diakses 12 januari 2010) 